\title{
MONITORING OF CONCRETE CURING IN EXTRADOSED BRIDGE SUPPORTED BY NUMERICAL SIMULATION
}

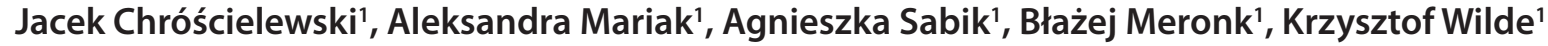 \\ 1 Faculty of Civil and Environmental Engineering, Gdansk University of Technology, Narutowicza 11/12, 80-233 \\ Gdańsk, Poland, e-mail: aleksandra.mariak@pg.gda.pl
}

Received: 2016.08.15

Accepted: 2016.10.26

Published: 2016.12.01

\begin{abstract}
The paper describes a mathematical model of concrete curing taking into account kinetics of setting reactions. The numerical model is implemented in the author's program that was used to monitor thermal effects recorded in the concrete bottom plate of the extradosed bridge. Numerical approach was verified by experimental measurements and used for assessment of the current compressive strength due to degree of hydration of fresh concrete.
\end{abstract}

Keywords: monitoring system, simulations, concrete maturity, bridge

\section{INTRODUCTION}

Nowadays structural health monitoring (SHM) systems are applied to large variety of engineering structures [18] including concrete infrastructure objects. SHM systems are equipped with standard displacement or strain sensors but can also be supported by other non-destructive diagnostic techniques like for example ultrasonic testing [e.g. 16]. SHM systems may rely solely on measurement data but may conduct advanced simulations and analysis of collected information [18, 17]. Modern measurement technologies supported by automated numerical examinations provides useful tools to monitor concrete maturity in building site. Information about the current parameters of the concrete is especially useful for concrete works at low temperatures, production of precast concrete elements or prestressed concrete elements. Knowledge of the real concrete strength allows to reduce time of construction phase and optimize work schedule. This approach is sometimes used during construction of bridges or multi-storey objects from high performance concrete. Monitoring of young concrete makes possible to limit damage generated by thermal and shrinkage effects and thus improves structure durability.

The measurement data combined with the appropriate mathematical description provide the ba- sis for estimating in situ strength [5]. Correlation of hydration degree (progress of a chemical reaction) with relatively simple to measure temperature of the hardening concrete is used to determine maturity index, which determines the stiffness and strength of the concrete $[2,4,5,13]$.

The paper presents the monitoring system implemented on the extradosed bridge constructed in the north of Poland and discusses numerical modelling of the concrete curing in bottom plate of the box -girder bridge. The measurement data and laboratory tests provides the strength-maturity relationship curve.

\section{DESCRIPTION OF THE EXTRADOSED BRIDGE}

The considered object is a 4-span road bridge (Figure 1). The total length of the structure equals $677.0 \mathrm{~m}(2 \times 132.5 \mathrm{~m}+2 \times 206.0 \mathrm{~m})$. The superstructure of the bridge is typical and has form of a three-chambered box with a total width of $28.4 \mathrm{~m}$ (Figure 2) made of prestressed concrete $\mathrm{C} 60 / 75$ class. The bridge is designed for class load A according to PN-85/S-10030 code and STANAG 2021 class 150 . The main cross-sectional dimensions and slopes are constant over the entire length 


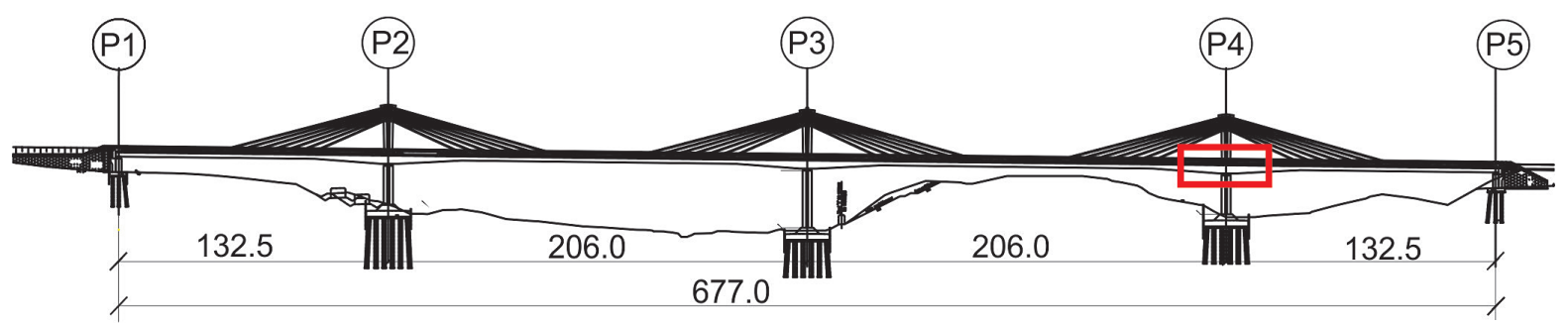

Fig. 1. View of the bridge [19]

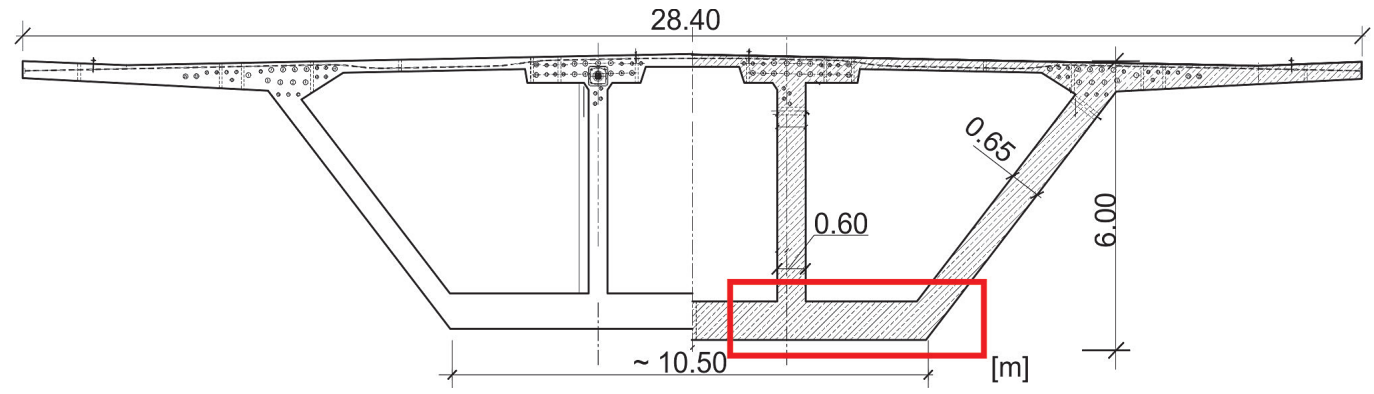

Fig. 2. Section of box-girder bridge in support zone [19]

of the object. The deck height changes from $4 \mathrm{~m}$ in spans to $6 \mathrm{~m}$ in the support zones. The concrete maturity monitoring was implemented in the bottom plate of the starting section (section A-A and $\mathrm{B}-\mathrm{B}$ ), whose thickness varies between $\sim 0.8 \mathrm{~m} \sim$ $1.4 \mathrm{~m}$ (Figure 3). In this section, vertical exterior walls of the box are $0.65 \mathrm{~m}$ thick and internal walls are $0.6 \mathrm{~m}$ thick. The object was carried out in two phases. The first section was performed on stationary scaffold (Figure 4) and the next segments are built in free cantilever technology.

\section{CONCRETE MONITORING SYSTEM}

The monitoring system has a function of collecting measurement data, transferring data on line and informing the user about the state of the

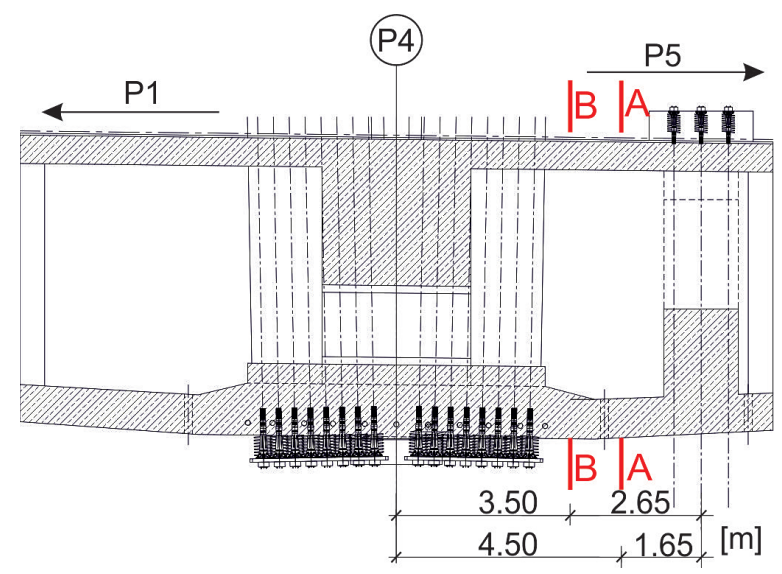

Fig. 3. Longitudinal section in support P4 [19] concrete element. An integral component of the monitoring system is a specially dedicated for this purpose, packet of applications for structural analysis based on numerical simulations [8]. Calculations using numerical model enable to predict the temperature and strength changes of known geometry and material parameters in structural elements. This approach allows to optimize the location of sensors and data collecting devices, and therefore, rationalize the cost of their implementing.

The system consists of three modules: measurement, expert and communication. The measuring module is responsible for the collection and storage of the data from sensors and devices. The expert module analyzes the state of hydration progress in real time. The communication module of the system informs the user about the actual level of compressive strength or Young modulus of concrete.

Temperature measurements were carried out using self-developed sensor system. The electronic device recognizes the 1-wire sensors on the basis of 16 digital serial numbers. Parameters of 1-wire interface allow to connect sensors on single wire of up to $300 \mathrm{~m}$. This feature makes the mounting of the sensors relatively simple comparing to the standard temperature devices that use different wire for each temperature sensor. The developed system enables to measure temperature in range of $-55^{\circ} \mathrm{C}$ to $+125^{\circ} \mathrm{C}$ with an accuracy of $\pm 0.5^{\circ} \mathrm{C}$ (Figure 5). 
a)

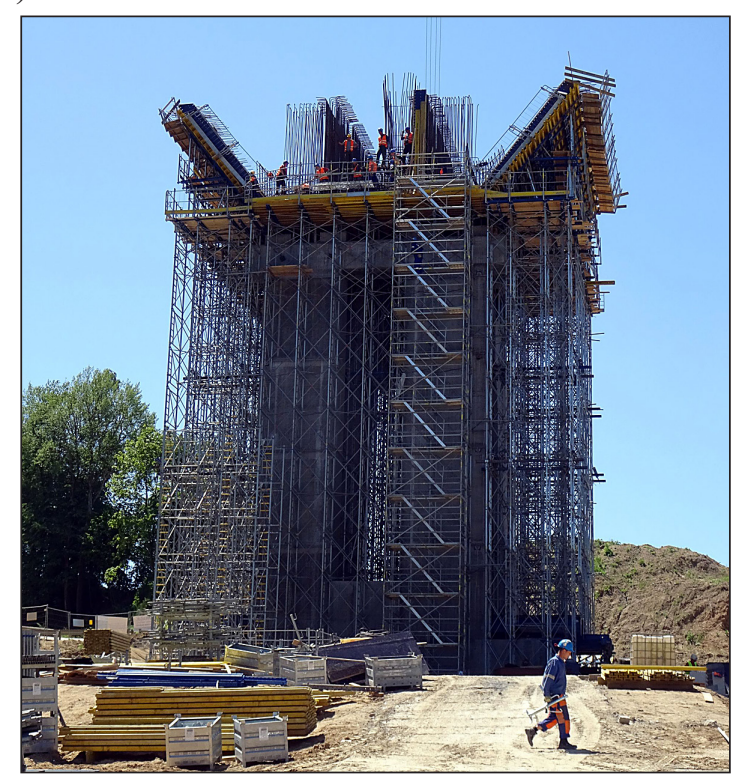

b)

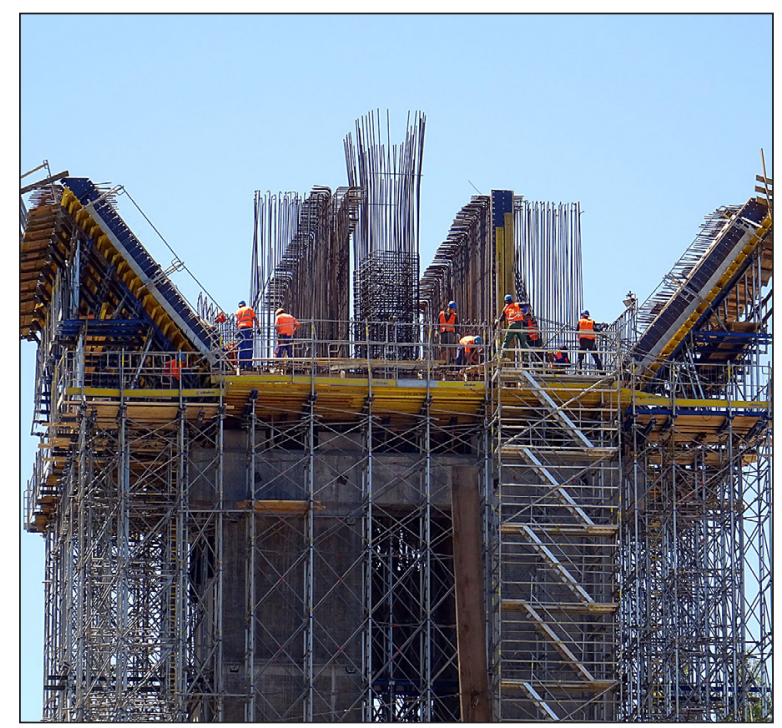

Fig. 4. First section on stationary scaffold (a), view of the deck section (b)

a)

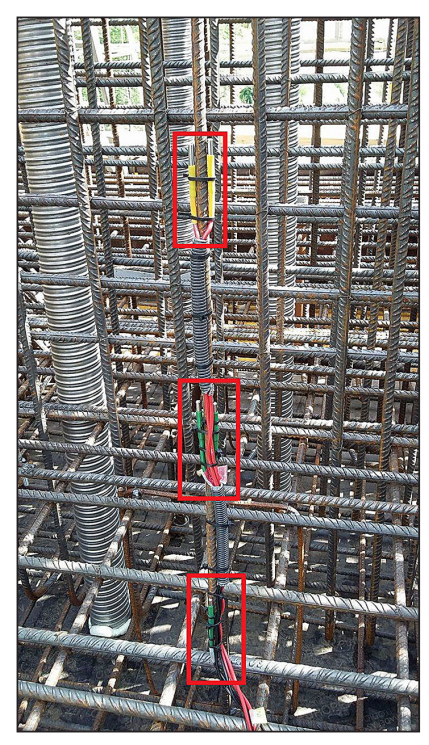

b)

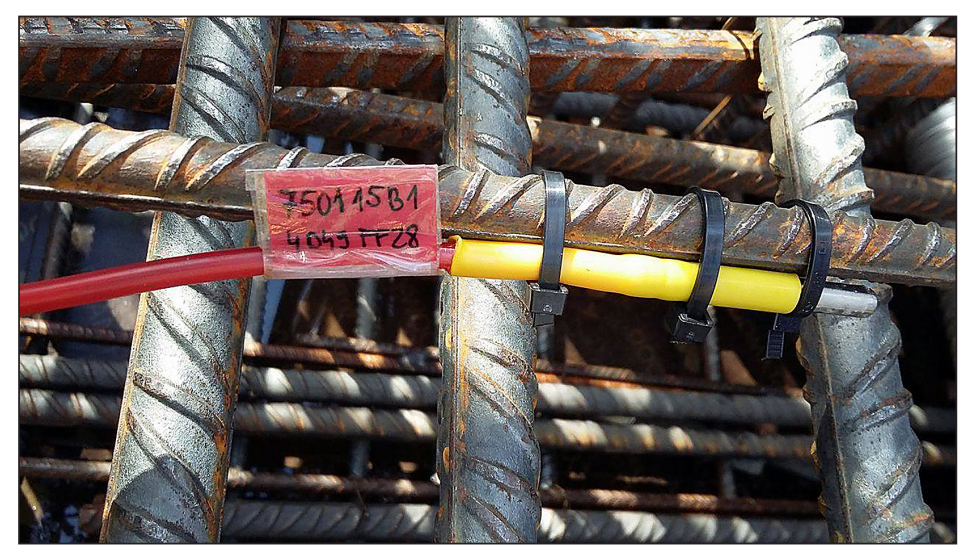

c)

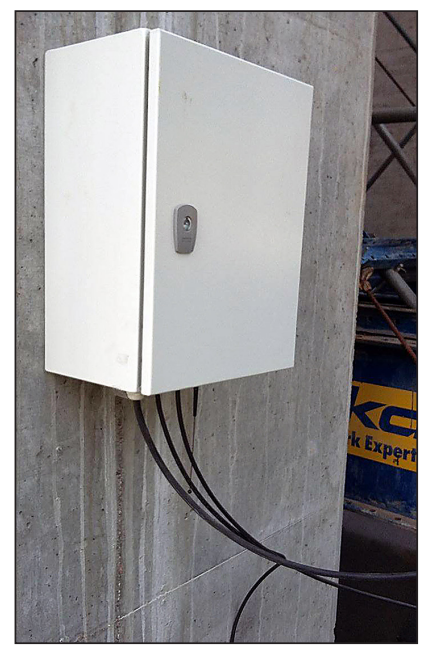

d)

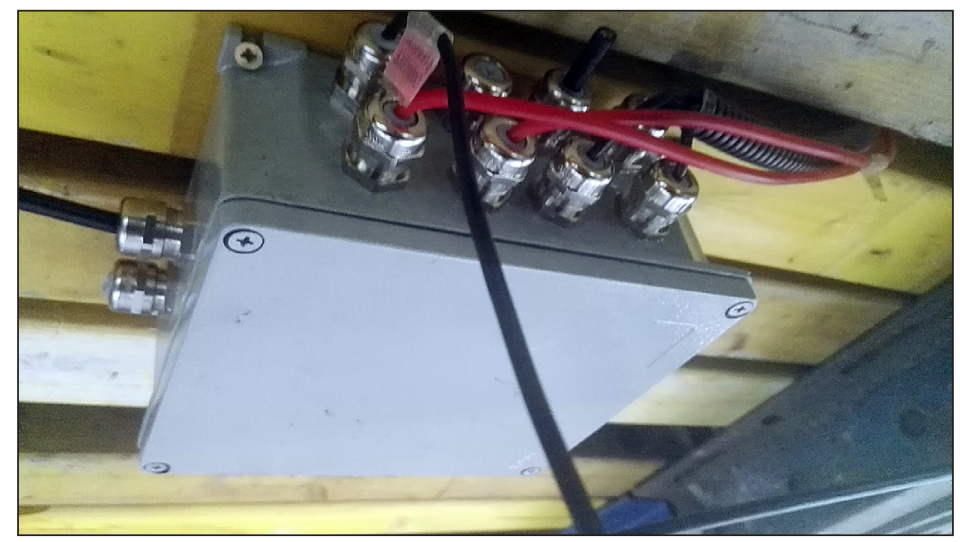

Fig. 5. Temperature sensors in plate section (a), 1-wire sensor mounted on reinforcement bar (b), central recording device (CRD) with a GSM module (c), component of the system mounted on the formwork (d) 
The locations of temperature measurement points are shown in Figure 6. In A-A section the points are located symmetrically in the plate thickness direction. In B-B section, point $\mathrm{p} 4$ is located at a depth of $0.23 \mathrm{~m}$ from the top of the surface. Additionally ambient temperature changes over the plate (point o1) and under the formwork (point 02 ) were registered.

\section{HYDRATION PROCESS}

The result of setting reaction is the cement slurry transition from the plastic state to a rigid state, accompanied by heat emission. Portland clinker minerals such as calcium silicates $\left(\mathrm{C}_{3} \mathrm{~S}\right.$ and $\left.\mathrm{C}_{2} \mathrm{~S}\right)$, calcium aluminates $\left(\mathrm{C}_{3} \mathrm{~A}\right)$ and calcium iron aluminates $\left(\mathrm{C}_{4} \mathrm{AF}\right)$ react with water and form a gel and crystalline phases hydrates. This process is particularly important in the first few days of concrete hardening. Three phases of the concrete life are highlighted in Figure 7. The first phase develops relatively slowly and involves mixing, transport, casting and curing in the formwork. After the final setting time $t_{o}$ is reached the hardening process (hardening phase) develops and sudden increase of the temperature can be observed [3]. During the hydration of $1 \mathrm{~g}$ of cement about 500 $\mathrm{J}$ of heat is emitted. Since the thermal conductivity of the concrete is relatively low, the temperature of the inner layers of the concrete grows the most. At the same time the outer parts of concrete lose the heat, and therefore, a temperature gradients are formed that may cause cracks initiation [15]. While the reaction advances, the porosity of the concrete decreases leading to the strength in-
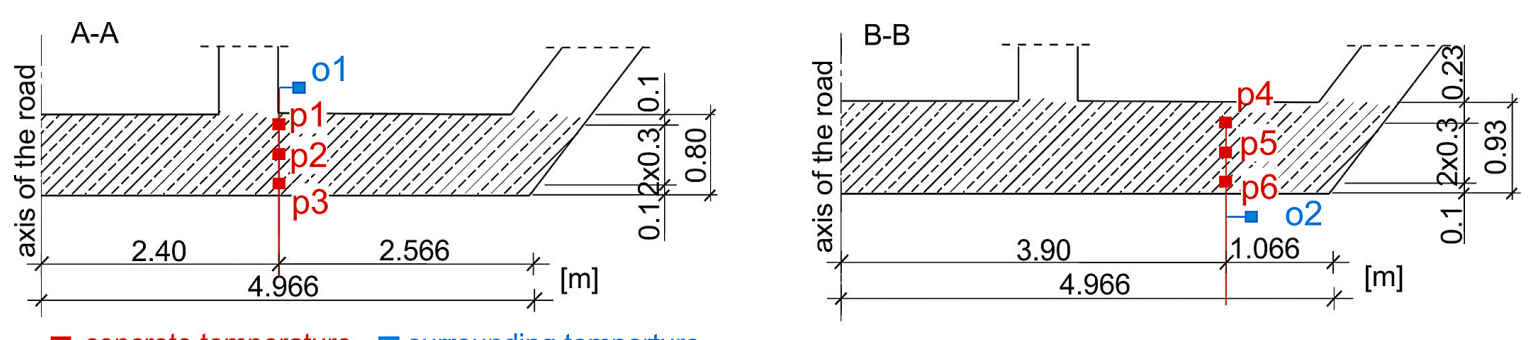

Fig. 6. Location of temperature measurement points, section A-A and B-B

a)

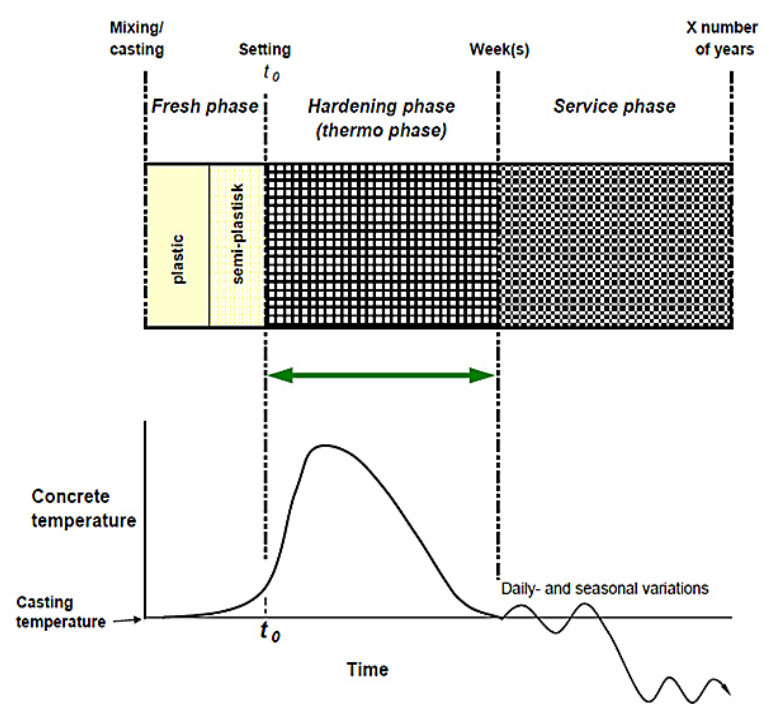

b)

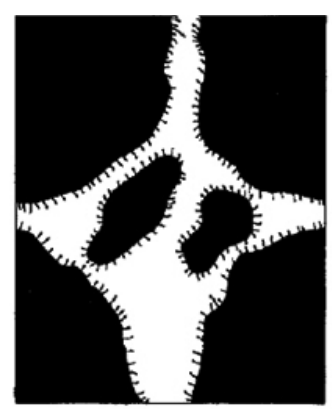

fresh phase

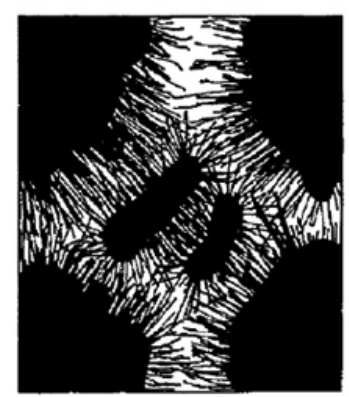

hardening phase

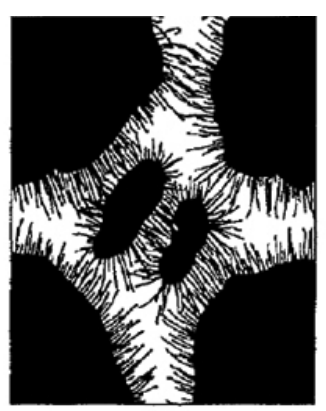

time $t_{0}$ - producing a stiff skeleton

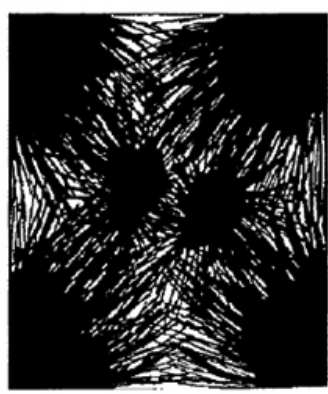

long-term complete hydration

Fig. 7. Schematic diagram of concrete life phases (a), phases of cement hydration (b) [3] 
crease. Finally, thermal equilibrium with the surrounding air is achieved and the concrete enters the service phase. At that time daily and seasonal variations of the temperature can be observed.

\section{THEORETICAL MODEL}

There is a large number of models of concrete curing that takes into account changes in temperature, moisture, the rate of chemical reactions as well as mechanical effects. Relatively well recognized is the thermo-hygro-mechanical model that includes development of shrinkage cracks. For example the model of Azenha [1] is formulated with respect to: the temperature field, relative humidity and displacements as well as the development of cracks. The system of equations includes the heat, moisture and momentum balance with the boundary conditions for the heat flow. The volumetric heat generation rate due to cement hydration is formulated as an Arrhenius type law $\dot{\xi}=A_{\theta} f(\xi) \exp \left(\frac{E_{a}}{R T}\right)$, in which the global progress is expressed as $\xi=Q / Q_{\infty}$, where the real amount of heat $Q_{\infty}$ is taken from the experiment. In this perspective, the chemical reactions influence is reduced to the internal heat source consideration. This heat emission is determined on the basis of temperature value provided by on line measured data. Moreover based on the temperature distribution, moisture field of concrete is established. This requires proper definition of the diffusion moisture coefficient, moisture stream and moisture transfer coefficient from the porous medium by air or water. The mechanical part is engaged with the moisture field through shrinkage strain and with thermal field through strain by thermal expansion.

An extension of the Azenha's model is Di Luzio-Cusatisa approach [7] where a chemo-thermo-hygro-mechanical model with two reactions is proposed. The heat source comes from two leading chemical phenomena: cement hydration and silica-fume reaction. Other improvements consist in: variation all constant in the heat and moisture transport equations, the presence of internal moisture sources coming from the reaction and above all the inclusion of visco-creep phenomena in the mechanical part.

The above models provide good insight into the process of concrete curing, however, they are very complex and difficult to apply for engineering problems were primary goals are of techno- logical nature. Therefore, the present model is focused on thermal aspect of concrete maturity and the integral technical parameters used by engineers controlling concrete curing process. These parameters must have a clear technical sense, should be easily measurable by monitoring systems and should have their counterparts in the mathematical model.

The non-uniform temperature field $T(x, t)$ of hardening concrete depends on type and amount of cement, conductivity, heat capacity of the concrete components, the intensity of heat exchange with surrounding, initial temperature of the concrete mixture, ambient temperature, concrete element dimensions and additional boundary conditions like neighborhood of already finished concrete elements that can release heat.

According to Cervera and others [5] thermodynamic field equation describing young concrete can be written in the following form:

$$
C \dot{T}+\nabla \cdot \boldsymbol{Q}_{f}=\dot{Q},
$$

where: $T$-temperature $[K]$,

$C$ - heat capacity $\left[\mathrm{J} /\left(\mathrm{m}^{3} \cdot K\right)\right]$,

$Q$ - internal heat source $\left[\mathrm{J} /\left(\mathrm{m}^{3} \cdot \mathrm{s}\right)\right]$,

$\dot{Q}=Q_{\infty} \dot{\xi}-$ rate of internal heat source $[W /$ $\mathrm{m}^{3}$,

$Q_{f}=-k_{T} \nabla T-$ heat flux (Fourier's law) $\left[W / \mathrm{m}^{2}\right]$,

$k_{T}$ - thermal conductivity $[\mathrm{W} /(\mathrm{m} \cdot \mathrm{K})]$,

$Q_{\infty}$ - total heat $\left[\mathrm{J} / \mathrm{m}^{3}\right]$,

$\xi=Q / Q_{\infty}-$ hydration degree $\left[s^{-1}\right]$

$\dot{\xi}$ - hydration rate [-].

The chemical process of concrete hardening is a function of the hydration degree $\dot{\xi}=$ $\tilde{A}_{\xi}(\xi) \exp \left(E_{a} T^{-1} R^{-1}\right)$, but since the reaction of water and cement is thermally activated, the dominant mechanism in the kinetics of the reaction amplifies Arrhenius type law $\psi=\exp \left(-\frac{E_{a}}{R \cdot T}\right)$ depending on temperature, the gas constant $R$ and activation energy $E_{a}[11]$.

The rate of hydration degree describes equation:

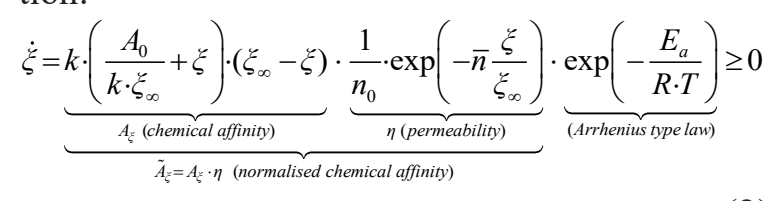

The normalised chemical affinity $\tilde{A}_{\xi}=A_{\xi} \cdot \eta$ is expressed through chemical affinity $A_{\xi}$ and permeability of water through the hydrates $\eta$. Material parameters $k, A_{0}, \xi_{\infty}, n_{0}, \bar{n}$ are determined 
experimentally. Equation (2) shows that heat activation expressed by Arrhenius factor is the most important in the initial phase of the reaction. During hydration process reaction is slowing down to achieve final value $\xi=\xi_{\infty}$. The evolution expressed in equation (2) with positive condition $\dot{\xi} \geq 0$ contains the basic requisites for a realistic simulation of the concrete hydration process [5].

\section{NUMERICAL SOLUTION}

The purpose of this example is simulation of temperature changes in bridge concrete plate throughout the plate thickness. It is assumed that the concrete curing is homogeneous and isotropic phenomenon with respect to the surface coordinates, hence spatial discretization is applied only to the plate thickness. Numerical tests have been carried out in B-B section where the thickness of the plate equals $0.93 \mathrm{~m}$ (Figure 6).

The solution of thermo-dynamic system of non-linear equations (1) and (2) requires two types of approximation, in space domain and time domain taking into account appropriate initial and boundary conditions and fulfilling convergence condition. Finite element method (FEM) solution expects variational formulation with interpolation $\mathrm{C}^{0}$ class. Another way is to use the finite difference method (FDM) and direct solution of the differential equation. Knowledge of $T(\boldsymbol{x}, t), \xi(\boldsymbol{x}, T$, t) fields allows one to estimate the strength and stiffness parameters of hardening concrete.

The parameters of high performance concrete C 60/75 class derived by the laboratory tests were taken after $[5,6,10]$. Table 1 shows constants determined under adiabatic conditions and used in the following numerical analysis.

The solid line in Figure 8 shows the concrete temperature changes at points $\mathrm{p} 4-\mathrm{p} 6$ and air temperature registered under the formwork at the construction site. The initial temperature of the concrete mixture was $24{ }^{\circ} \mathrm{C}$. Temperature increase is clearly visible after 3 hours from the concrete casting and the maximum value was reached in $30^{\text {th }}$ hour in central point $\mathrm{p} 5\left(68.6^{\circ} \mathrm{C}\right)$. Temperature data are the basis for making decision about using thermal insulation or uncovering individual zones of the surface element. In order to balance the temperature in the initial stage of hardening (hot region in the core, cooler one close to the external surface), the plate has been covered with 5 $\mathrm{cm}$ thick styrofoam between $27-96$ hours. The effect of the upper surface insulation is particularly visible at the point $\mathrm{p} 4$ located close to the plate top surface. The changes in plate insulation protected the concrete against exceeding the temperature gradients permitted in the bridge project.

The results of temperature simulations are indicated in Figure 8 by dashed lines. The calculations assume constant ambient temperature of 20.3 ${ }^{\circ} \mathrm{C}$ at the top and bottom of the plate as the average of points 01 and 02 . The simulations did not take into account the temperature changes due to the sun exposure and changes of sun position with respect to the concrete segment. A very good agreement between the measurements and simulations in the points $\mathrm{p} 4, \mathrm{p} 5, \mathrm{p} 6$ has been achieved. The biggest temperature difference of about $4{ }^{\circ} \mathrm{C}$ is visible for the points $\mathrm{p} 4$ and $\mathrm{p} 5$, and at point $\mathrm{p} 6$ this difference is only $2{ }^{\circ} \mathrm{C}$. After 14 days the values of the temperatures in each measurement points is stabilizing.

The simulations of temperature profiles in the thickness direction at 12, 48, 96, 204, 336 hour is shown in Figure 9. The measured values are indicated by dots, the simulation results representing a growing temperature phase are denoted by solid lines and the cooling phase by dashed line. The measured temperature profiles are in a very good agreement with the theoretical prediction. The relative errors between the predicted values and the experimental ones do not exceed $2 \%$. Only at the point $\mathrm{p} 4$, after $12 \mathrm{~h}$ the relative error reached $6 \%$. It is probably due to the fact that from 5 to 14 hours the largest temperature rate was observed.

The applied theoretical model and precise determination of the boundary conditions enables accurate prediction of temperature changes and finally prediction of the mechanical properties of the hardening concrete.

\section{STRENGTH ESTIMATION}

Monitoring of concrete curing at early age is useful to assess the advancement of harden-

Table 1. Material properties

\begin{tabular}{|c|c|c|c|c|c|c|c|c|c|c|c|}
\hline$W / c[-]$ & $\xi_{\infty}[-]$ & $k / n_{0}\left[\mathrm{~h}^{-1}\right]$ & $k_{T}\left[\mathrm{~W} /\left(\mathrm{m}^{\circ}{ }^{\circ} \mathrm{K}\right)\right]$ & $A_{0} / k[-]$ & $Q_{\infty}\left[\mathrm{J} / \mathrm{m}^{3}\right]$ & $T_{0}\left[{ }^{\circ} \mathrm{C}\right]$ & $\bar{n}[-]$ & $C\left[\mathrm{~J} /\left(\mathrm{m}^{3} \cdot{ }^{\circ} \mathrm{C}\right)\right]$ & $E_{a} / R\left[{ }^{\circ} \mathrm{K}\right]$ & $f_{\infty}[\mathrm{MPa}]$ & $T_{r}\left[{ }^{\circ} \mathrm{C}\right]$ \\
\hline 0.325 & 0.65 & $1.9 \times 10^{7}$ & 1.7 & $5 \times 10^{-6}$ & $1.95 \times 10^{8}$ & 24 & 5.5 & $2.16 \times 10^{6}$ & 4875 & 75.2 & 20 \\
\hline
\end{tabular}




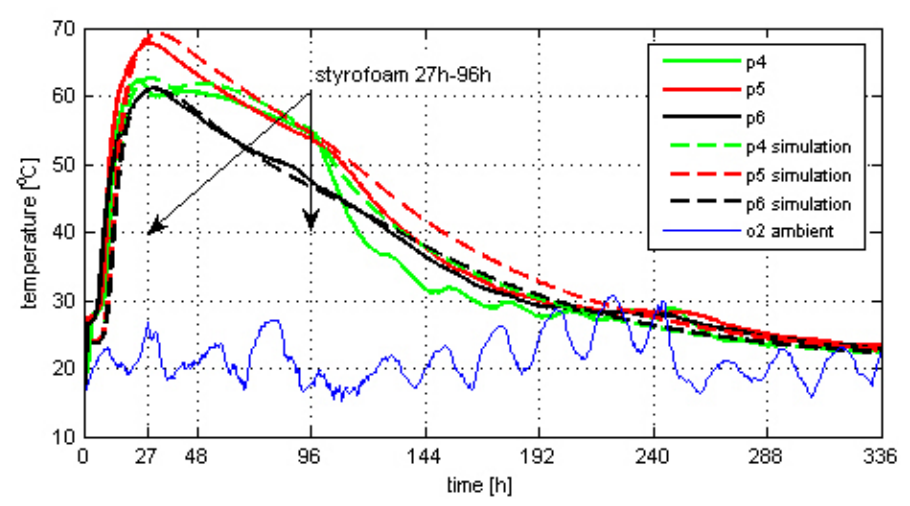

Fig. 8. Temperature evolution in section B-B, first 14 days

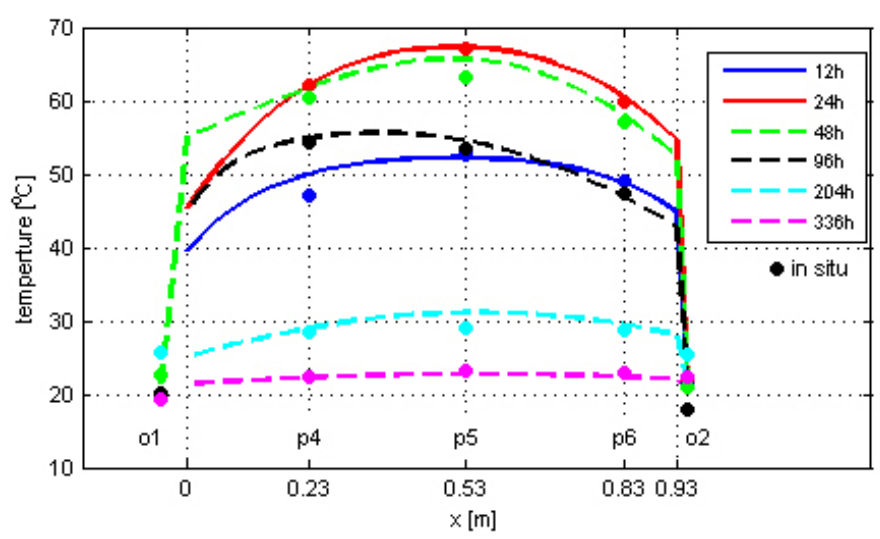

Fig. 9. Temperature profile, section B-B

ing from the time of produce mixture to achieve required strength. In the Nordic countries and United States maturity time is commonly used to assess compressive strength. The development of mechanical properties of the concrete is closely related to the degree of hydration, which is a kind of index of a chemical reaction progress. Concrete strength and Young modulus increase with the progress of the hydration, and the rate of hydration of concrete increases with increasing temperature. This relationship indicates the ability to describe strength changes as a function of time and temperature of concrete $[3,4,9,12]$.

The maturity method for estimating concrete strength is based on calculation of the maturity index, expressed either in terms of the of temperature-time factor TTF or as an age equivalent $t_{e}$ at a reference temperature. In Europe, the reference temperature $T_{r}$ is generally set to $20^{\circ} \mathrm{C}$, being related to the $\dot{\xi}^{r}$ equal 1.0. Temperatures above 20 ${ }^{\circ} \mathrm{C}$ provide $\dot{\xi}>1.0$, and below $20^{\circ} \mathrm{C}$ then $\dot{\xi}<1.0$. It is worth to notice that, at around $-10^{\circ} \mathrm{C}$ hydration practically stops $(\dot{\xi}=0)[3]$.

The maturity function of the concrete used in this paper is formulated with the use of the exponential Arrhenius equation. This function calculates maintenance interval in a specified temperature to the equivalent age in reference temperature $T_{r}$. Equivalent age is expressed in the following form:

$t_{e}=\int_{0}^{t} f(T) d t=\int_{0}^{t} \exp \left[Q\left(\frac{1}{T_{r}}-\frac{1}{T_{i}}\right)\right] d t=\sum_{i=1}^{n} \exp \left[Q\left(\frac{1}{T_{r}}-\frac{1}{T_{i}}\right)\right] \Delta t$

where: $t_{e}$ - equivalent age [h],

$\stackrel{e}{Q}$ - activation energy divided by the gas constant $[\mathrm{K}]$,

$T_{i}$ - average temperature of concrete during time interval $\Delta \mathrm{t}[\mathrm{K}]$,

$T_{\mathrm{r}}$ - reference temperature $[\mathrm{K}]$,

$\Delta t$ - time interval $[\mathrm{h}]$.

Although the hydration degree is not directly introduced in this formula, the assumed cumulative influence $\left(t_{e}^{\text {cum }}\right)$ of the temperature on the curing process is such that different thermal conditions could result in the same maturity and consequently the same final strength. The realistic maturity model should take into account the influence of the hydration degree $\xi$ and effect of the curing temperature. 
The strength-maturity relationship for a specific recipe of concrete mixture requires at least 28 days study before concrete in building site. The first stage of research includes laboratory tests carried out on cubic and cylindrical concrete specimens and the second stage is the concrete monitoring during curing in-place [12]. For each concrete mix, the general steps for implementing maturity are:

- laboratory testing and determination of maturity curve,

- set up temperature and maturity monitoring equipment in the field,

- collecting of temperature and maturity data,

- performing numerical simulation of hydration process,

- estimation of concrete strength using calculated maturity curve,

- validation break test specimens to verify strength.

The aim of the research is the estimation of inplace strength of box-girder bridge made from the high performance concrete, C60/75 class. Due to the large length of span $(206.0 \mathrm{~m})$, the contractors have chosen the free cantilever method to build the prestressed bridge. The free cantilever technology consists in developing the bridge structure by individual parts, the so-called segments. Segments are concreted into formwork fixed to a special movable steel structure - form traveller. In order to optimize the pace of construction segments, the knowledge of in situ concrete strength is necessary.

The success of estimating compressive strength by in situ measurements ensures proper maturity function. The extensive laboratory tests was carried out on mortar cubes $50 \mathrm{~mm}, 150 \mathrm{~mm}$

a)

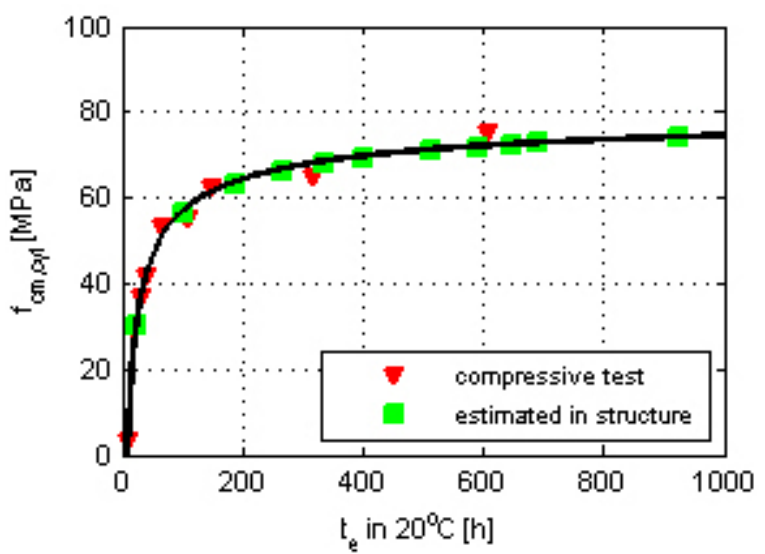

concrete cubes and concrete cylinders 150 to 300 $\mathrm{mm}$ allowed to find $Q$ parameter from equation (3). Hence the maturity function applied in bridge construction site can be calculated from following equation:

$$
t_{e}=\sum_{i=1}^{n}\left[4875\left(\frac{1}{293}-\frac{1}{T_{i}}\right)\right] \Delta t
$$

Based on the above equation, compressive strength from breaking tests and temperature measurements of concrete samples, the maturity curve has been plotted. Continuous temperature measurement in the bottom plate allowed to calculate maturity index and estimate strength of the hardening concrete. According to the curves in Figure 10, required to prestressing, $60 \%$ of 28 day strength was reached in 1 day after starting of concrete. Followed by the breaking test (traditional method for estimation strength), the time required to start prestressing would extend to the 2 working days. In this case, monitoring of concrete curing allows a significant acceleration of the work schedule.

\section{CONCLUSIONS}

The paper presents a model of concrete curing and its implementation validated on the example of the bottom plate of extradosed bridge. The study led to the following conclusions:

1. The developed temperature measurement system, based on 1-wire technology, proved to be useful and easy to mount inside the bridge concrete elements;

2. The proposed numerical model of concrete curing provides good agreement between

b)

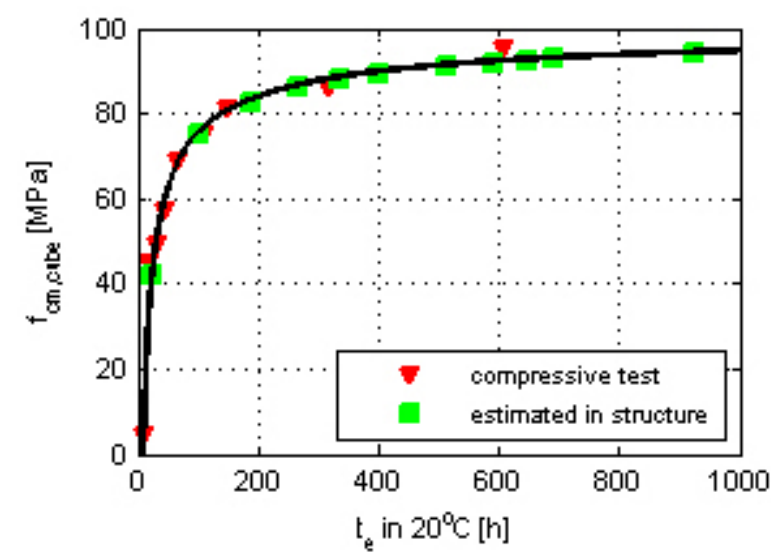

Fig. 10. Maturity curve: a) cylindrical strength; b) cubic strength 
measured and numerical data;

3. The considered monitoring procedures allow to determine true strength and stiffness properties of concrete at the early stage of hardening.

The monitoring of concrete curing process at the construction site may allow to build faster, and therefore, save money. Furthermore, it is not necessary to test a large number of beam samples, test cylinders and cubes in a lab, as it is required in traditional construction. The monitoring of concrete maturity may also help to control the quality of the concrete mixture. The improvement of competitiveness of constriction business requires new innovative technologies that can be developed only in close cooperation between universities and industry [14].

\section{Acknowledgements}

The authors wish to thank Professor Janusz Badur from Institute of Flow Machinery Polish Academy of Science for his priceless comments and contribution in selecting the model of young concrete as well as Wilde Engineering Company for providing the equipment and technical support in conducting the monitoring of concrete curing at the construction site.

\section{REFERENCES}

1. Azenh M., Sousa C., Faria R. and Neves A. Thermo-hygro-mechanical modelling of self-induced stresses during the service life of RC structures. Engineering Structures, 33, 2011, 3442-3453.

2. Bentz D.P., Waller V. and De Larrard F. Prediction of adiabatic temperature rise in conventional and high-performance concretes using a $3 \mathrm{D}$ microstructural model. Cement Concrete Reasearch, 28(2), 1998, 285-297.

3. Bjøntegaard Ø. Basis for and practical approaches to stress calculations and crack risk estimation in hardening concrete structures - State of the art., Norwegian Public Roads Administration, 2011.

4. Carino N.J. and Lew H.S., The Maturity Method: From Theory to Application. Proc. of the Structures Congress \& Exposition, Washington, D.C., American Society of Civil Engineers, Reston, Virginia, 2001.

5. Cervera M., Faria R., Oliver J. and Prato T. Numerical modelling of concrete curing, regarding hydration and temperature phenomena. Computers and Structures, 80, 2002, 1511-1521.

6. De Schutter G. and Taerwe L. General hydration model for Portland cement and blast furnace slag cement. Cement Concrete Reasearch, 25(3), 1995, 593-604.

7. Di Luzio G. and Cusatis G. Solidification-microprestress-microplane (SMM) theory for concrete at early age: Theory, validation and application. International Journal of Solids and Structures, 50, 2013, 957-975.

8. Kaminski W., Makowska K., Miśkiewicz M., Szulwic J. and Wilde K. System of monitoring of the Forest Opera in Sopot structure and roofing. Proc. of 15th International Multidisciplinary Scientific GeoConference SGEM 2015, SGEM2015 Conference Proceedings, 2 (2), 2015, 471-482.

9. Kaszyńska M. Early age properties of highstrength/high-performance concrete. Cement and concrete composites, 24, 2002, 253-261.

10. Kim J.-K., Moon Y.-H. and Eo S.-H. Compressive strength development of concrete with different curing time and temperature. Cement Concrete Reasearch, 28(2), 1998, 1761-1773.

11. Mariak A. and Wilde K. Exponential Arrhenius equation as a function of concrete maturity. Monografie Technologii Betonu, IX Dni betonu, in polish, 2016, 611-626.

12. Mariak A. and Wilde K., Estimating the strength of concrete based on the maturity function according to standards ASTM C1074-11. Materiały Budowlane 4, (in Polish), 2015, 68-71.

13. Martinelli E., Koenders E.A.B. and Caggiano A. A numerical recipe for modelling hydration and heat flow in hardening concrete. Cement \& Concrete Composites. 40, 2013, 48-58.

14. Miśkiewicz M., Okraszewska R. and Pyrzowski Ł. Composite footbridge - synergy effect in cooperation between universities and industry. Proc. of 7th International Conference of Education, Research and Innovation, ICERI Proceedings, Seville, Spain 2014, 2897-2903.

15. Neville A.M., Properties of concrete. Polski Cement. Kraków, 2000.

16. Rucka M. and Wilde K. Experimental study on ultrasonic monitoring of splitting failure in reinforced concrete. Journal of Nondestructive Evaluation, 32 (4), 2013, 372-383.

17. Rucka M. and Wilde K. Neuro-wavelet damage detection technique in beam, plate and shell structures with experimental validation. Journal of Theoretical and Applied Mechanics, 48(3), 2010, 579-604.

18. Sohn H., Farrar C., Hemez F., Shunk D., Stinemates D., Nedler B. and Czarnecki J. A Review of Structural Monitoring Literature 1996-2001, Los Alamaos National Laboratory, 2004.

19. Stefanowski T. Construction project of the expressway S7 section Miłomłyn-Olsztynek, bridge MS3/B DK-16, Transprojekt Gdański, in Polish, 2016. 